\title{
The Thickness of Epicardial Adipose Tissue Adjacent to the Right Coronary Artery Predicts Recurrence of Atrial Fibrillation After Cryoballoon Ablation: A Simpler Method
}

\author{
NS Yelgeç', S Şahin ${ }^{2}$, AT Alper ${ }^{1}$
}

\begin{abstract}
Objective: Epicardial adipose tissue (EAT) is a metabolically active tissue and increased thickness is correlated with various cardiovascular diseases. There are various ways to estimate EAT. In this study, we investigated the predictive value of EAT thickness adjacent to the right coronary artery (RCA) for late atrial fibrillation (AF) recurrences in patients treated with cryoballoon ablation (CBA). We propose that this method is simpler than other methods for measurement of EAT on multidetector computed tomography images.

Methods: Patients with symptomatic paroxysmal or persistent AF despite one or more antiarrhythmic drugs who were scheduled for CBA were prospectively recruited. Multidetector computed tomography was performed and epicardial adipose tissue thickness was measured as the fat-thickness from the epicardium to the myocardium around the RCA just after the acute marginal branch. The duration of follow-up was 12 months and AF recurrence was defined as an episode of AF longer than 30 seconds duration occurring three months after CBA. The study population included 72 patients and in 22 patients (30.5\%) AF recurrence was observed.

Results: Epicardial adipose tissue thickness was significantly higher in patients who had late recurrent AF compared to the patients without late recurrence $(12.3 \pm 3.2$ vs $10.2 \pm 3.2$, p < 0.01). Highly sensitive C-reactive protein ( $H s-C R P)$ level and left atrial (LA) volume index were significantly higher in the recurrent AF group compared to patients without AF recurrence. Multivariable analysis showed that LA volume index (OR 1.41, $95 \%$ CI:1.15, 1.73, p $<0.01), h s-C R P(O R$ 1.42, 95\% CI:1.02, 1.94, $\mathrm{p}=0.04)$ and EAT thickness (OR 1.34, 95\% CI:1.05, 1.71, $\mathrm{p}=0.02)$ remained as independent predictors of AF recurrence in the study population.

Conclusion: Epicardial adipose tissue thickness adjacent to the RCA is associated with late AF recurrences in patients treated with CBA. This method of EAT quantification seems to be simpler, less time-consuming and may be an alternative to other methods of EAT measurement.
\end{abstract}

Keywords: Atrial fibrillation, cryoballoon ablation, epicardial adipose tissue, recurrence

From: ${ }^{1}$ Department of Cardiology and ${ }^{2}$ Department of Radiology, Dr Siyami Ersek Thoracic and Cardiovascular Surgery Training and Research Hospital, Istanbul, Turkey.
Correspondence: Dr N Yelgeç, Department of Cardiology, Dr Siyami Ersek Thoracic and Cardiovascular Surgery Training and Research Hospital, 34668 Üsküdar-Istanbul, Turkey. Email: yelgec@gmail. com 


\title{
El grosor del tejido adiposo epicárdico adyacente a la arteria coronaria derecha predice la recurrencia de la fibrilación auricular después de la crioablación con balón: Un método más sencillo
}

\author{
NS Yelgeç ${ }^{1}, \mathrm{~S}$ Şahin², AT Alper ${ }^{1}$
}

\begin{abstract}
RESUMEN
Objetivo: El tejido adiposo epicárdico (TAE) es un tejido metabólicamente activo y el aumento del grosor se correlaciona con varias enfermedades cardiovasculares. Hay varias maneras de estimar el TAE. En este estudio, investigamos el valor predictivo del grosor del TAE adyacente a la arteria coronaria derecha (ACD) para las recurrencias tardias de la fibrilación auricular (FA) en pacientes tratados con crioablación con balón (CAB). Proponemos que este método es más simple que otros métodos para la medición del TAE en las imágenes de la tomografia computarizada con detectores múltiples.

Método: Pacientes con FA paroxistica sintomática o persistente - a pesar de uno o más fármacos antiarritmicos - que estaban programados para CAB, fueron reclutados prospectivamente. Se realizó la tomografía computarizada con detectores múltiples y el grosor del tejido adiposo epicárdico del tejido fue medido como el grosor de la grasa desde el epicardio al miocardio alrededor de la ACD, justamente tras la rama marginal aguda. La duración del seguimiento fue de 12 meses y la recurrencia de FA se definió como un episodio de FA de más de 30 segundos de duración ocurrido tres meses después de la CAB. La población de estudio incluyó 72 pacientes, y en 22 pacientes (30.5\%) se observó recurrencia de FA.

Resultados: El grosor del tejido adiposo epicárdico fue significativamente mayor en pacientes

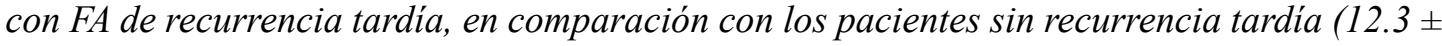
3.2 vs $10.2 \pm 3.2, \mathrm{p}<0.01)$. El nivel de la proteina $C$ reactiva altamente sensible (PCR-as) y el índice del volumen auricular izquierdo (AI) fueron perceptiblemente más altos en el grupo de FA recurrente en comparación con los pacientes sin FA recurrente. El análisis multivariable mostró que el índice de volumen AI (OR 1.41, 95\% IC: 1.15, 1.73, p <0.01), PCR-as (OR 1.42, 95\% IC: 1.02, 1.94, $\mathrm{p}=0.04)$ y el grosor del TAE (OR 1.34, 95\% IC: 1.05, 1.71, p = 0.02) permanecieron como predictores independientes de la recurrencia de FA en la población de estudio.

Conclusión: El grosor del tejido adiposo epicárdico adyacente a la ACD se halla asociado con las recurrencias tardias de FA en pacientes tratados con CAB. Este método de cuantificación de TAE parece ser más simple, consume menos tiempo, y puede ser una alternativa a otros métodos de medición de TAE.
\end{abstract}

Palabras clave: Fibrilación auricular, crioablación con balón, tejido adiposo epicárdico, recurrencia

West Indian Med J 2019; 68 (1): 2

\section{INTRODUCTION}

Catheter ablation (CA) of atrial fibrillation (AF) for rhythm control strategy is an effective method for alleviation of symptoms in patients with AF. The success of cryoballoon ablation (CBA) varies and there are many factors that affect ablation outcome such as: underlying cardiovascular disease (CVD), hypertension (HT), valvular heart disease, older age and persistent $\mathrm{AF}$
(1). Obesity, especially visceral adiposity, is related to inflammation and is associated with increased risk for CVD $(2,3)$.

Epicardial adipose tissue (EAT) is accepted as a component of visceral adipose depots and correlation of increased EAT with increased incidence of CVD and also AF have been shown (4-6). However, there is no standardized method for quantification of EAT, and 
different imaging modalities are used for this purpose. The process may be time-consuming, and each method has its own drawbacks. Multi-detector computed tomography (MDCT) images may be used for this purpose and measuring EAT thickness around the right coronary artery (RCA) after the acute marginal branch is a simpler method compared to other methods (7). In this study, we investigated the association between the thickness of the EAT and recurrence of AF after CBA and tested the effectiveness and clinical use of single EAT thickness measurement around the RCA with MDCT in prediction of AF recurrences.

\section{SUBJECTS AND METHODS}

\section{Study population}

This study was conducted in the Dr Siyami Ersek Thoracic and Cardiovascular Surgery Center, Training and Research Hospital, Department of Cardiology, Istanbul, Turkey, from September 2012 until June 2015. Seventy-two consecutive patients who underwent CBA for paroxysmal or persistent $\mathrm{AF}$ were prospectively recruited for this study. All of the patients were evaluated in the outpatient clinic and patients with drug refractory AF were scheduled for the CBA procedure. Transthoracic echocardiography (TTE) and/or transoesophageal echocardiography (TEE) were performed in order to exclude valvular heart disease and left atrial (LA) thrombi according to the established criteria (5). The clinical and demographic properties of the subjects such as age, gender, body mass index [BMI] $\left(\mathrm{kg} / \mathrm{m}^{2}\right)$, smoking history, co-morbidities (HT, diabetes mellitus (DM), hyperlipidaemia and coronary artery disease) medications and history of AF were recorded during outpatient visits.

All the patients had MDCT before the ablation procedure for pulmonary vein anatomy evaluation. Recurrences of AF that occur within the first three months after CBA were accepted as early recurrences and were not regarded as real AF recurrences. We defined recurrence as an episode of AF longer than 30 seconds duration, occurring three months after CBA. These patients served as the study group, and the remainder of the study population served as the control group. Follow-up examinations were performed at 1, 3, 6, 9 and 12 months after the procedure. At each visit, physical examination was performed, and symptoms related to any arrhythmias were evaluated. Twelve-lead electrocardiogram (ECG) was recorded, and 24-hour Holter monitoring was also performed at each visit.
Antiarrhythmic drugs were continued for at least three months, and anticoagulant drugs were continued for at least six months.

The study was in compliance with the principles outlined in the Declaration of Helsinki and approved by the Institutional Ethics Committee, and all of the patients gave written informed consent. The Local Ethics Committee of our Hospital approved the study protocol.

Among the patients who had been cryoablated, there was no patient with coronary luminal narrowing $>50 \%$, valvular heart disease, renal dysfunction (serum creatinine levels $>1.5 \mathrm{mg} / \mathrm{dL}$ ), hepatic disorders, concomitant inflammatory or neoplastic diseases, or any other systemic disorders including thyroid disorders.

\section{Echocardiography and multi-detector computed tomography imaging protocol}

All the individuals were examined by two experienced echocardiographers who were blinded to the laboratory data and clinical properties of the subjects. The standard evaluation included: M-mode, 2-dimensional and Doppler studies according to the recommendations of the American Society of Echocardiography (8). Computed tomography (CT) imaging was performed with a dualsource 64-slice MDCT scanner.

Epicardial adipose tissue thickness was measured as the fat-thickness from the epicardium to the myocardium around the right coronary artery just after the acute marginal branch.

We preferred this region because epicardial fat was thicker, well-defined and was less susceptible to motion artifacts. On the other hand, the possibility of confusing paracardiac fat with epicardial fat was lower. All the MDCT analyses were done by experienced physicians blinded to other information and the AF status of the patients. Intraobserver variability testing for repeated EAT measurements from 20 subjects revealed an intra-class correlation coefficient of 0.967 $(p<0.001)$.

\section{Electrophysiology and ablation procedure}

All the patients were sedated using midazolam. Then, by using the right femoral venous approach, transseptal puncture using the modified Brockenbrough technique was performed under fluoroscopic and transesophageal echocardiography (TEE) guidance. Standard cryoballoon ablation procedure was performed for each patient. 


\section{Statistical analysis}

The patient population was classified as patients with and without late AF recurrences. All the data presented as mean $\pm \mathrm{SD}$ or a median [interquartile range] for parametric variables and as percentages for categorical variables. Continuous variables were checked for the normal distribution assumption using KolmogorovSmirnov statistics. Categorical variables were tested by Pearson's Chi-square and Fisher's exact tests. The differences between patients and the control subjects were evaluated with independent samples $t$-test or MannWhitney U-test when appropriate. Correlations between two continuous variables were assessed with Pearson's test. Binary logistic regression analysis was used to find the possible independent association between AF and clinical and laboratory parameters. A $p$-value of $<0.05$ was considered statistically significant. All statistical studies were carried out using the Statistical Package for Social Sciences Software (SPSS 16.0 for Windows, SPSS Inc, Chicago, Illinois).

\section{RESULTS}

The study population comprised 72 patients. During the follow-up period of one year, early AF recurrence occurred in 21 cases, and late AF recurrence occurred in 22 cases $(30.5 \%)$. The study group included the patients with late AF recurrence, and the control group included

Table 1: Clinical and demographic properties of the patients with atrial fibrillation and the controls

\begin{tabular}{lrrr}
\hline & $\begin{array}{c}\text { Control } \\
(\mathbf{n}=\mathbf{5 0})\end{array}$ & $\begin{array}{c}\text { AF recurrence } \\
(\mathbf{n = 2 2})\end{array}$ & $\boldsymbol{p}$ \\
\hline Age, years & $54.5 \pm 12.1$ & $57.6 \pm 9.9$ & 0.26 \\
Male gender, n(\%) & $34(68)$ & $12(54)$ & 0.28 \\
Hypertension, n(\%) & $19(38)$ & $11(50)$ & 0.34 \\
Diabetes mellitus, n(\%) & $4(8)$ & $5(23)$ & 0.09 \\
Hyperlipidemia, $\mathrm{n}(\%)$ & $7(14)$ & $5(13)$ & 0.36 \\
Current smoker, $\mathrm{n}(\%)$ & $16(32)$ & $10(45)$ & 0.25 \\
Body mass index, $\mathrm{kg} / \mathrm{m}^{2}$ & $25.9 \pm 1.4$ & $26.5 \pm 1.2$ & 0.45 \\
EAT thickness, mm & $10.2 \pm 3.2$ & $12.3 \pm 3.2$ & $<0.01$ \\
Echocardiography parameters & & & \\
LVEDD, mm & $46.5 \pm 4.3$ & $46.9 \pm 4.6$ & 0.69 \\
LVESD, mm & $28.8 \pm 3.7$ & $29.7 \pm 3.5$ & 0.45 \\
IVS, mm & $9.6 \pm 0.9$ & $10.2 \pm 2.1$ & 0.15 \\
LV EF, \% & $58.8 \pm 3.9$ & $60.1 \pm 1.9$ & 0.19 \\
LA anteroposterior diameter, mm & $38.3 \pm 3.9$ & $42.4 \pm 4.5$ & $<0.01$ \\
LA volume, cm & $37.2 \pm 8.6$ & $43.2 \pm 10.6$ & $<0.01$ \\
LA volume index, cm ${ }^{3} / \mathrm{m}^{2}$ & $25.9 \pm 3.6$ & $30.7 \pm 4.2$ & $<0.01$ \\
\hline
\end{tabular}

Parametric variables with normal distribution were reported as mean \pm standard deviation. AF: atrial fibrillation, EF: ejection fraction, IVS: interventricular septum, LA: left atrium, LV: left ventricle, LVEDD: left ventricular enddiastolic diameter, LVESD: left ventricular end-systolic diameter.
50 patients without late AF recurrence. The demographic and echocardiographic properties of the study and the control groups are depicted in Table 1.

The frequency of HT, DM, hyperlipidaemia and smoking were similar between the groups. In addition, BMI, LV diameters and interventricular septum thickness were comparable between the groups. The LA anteroposterior diameter, LA volume and LA volume index were significantly higher in patients with recurrence compared to the control group. Epicardial adipose tissue thickness was also significantly higher in the AF group compared to the control $(12.3 \pm 3.2 v s 10.2 \pm 3.2 \mathrm{~mm}, p<0.01)$. The comparison of laboratory parameters is summarized in Table 2.

Haemoglobin level and lymphocyte count were lower in the recurrent AF group. High sensitive C-reactive protein (hs-CRP) level was significantly higher in the recurrent $\mathrm{AF}$ group compared to patients without $\mathrm{AF}$ recurrence $(0.69 \pm 0.21$ vs $0.51 \pm 0.20 \mathrm{mg} / \mathrm{L}, p<0.01)$. In univariate correlation analysis, EAT thickness was correlated with BMI $(\mathrm{r}=0.42, p<0.01)$ and hs-CRP levels $(\mathrm{r}=0.29, p=0.02)$ but was not correlated with age $(\mathrm{r}=0.08, p=0.53)$, LA volume index $(\mathrm{r}=0.05, p=$ $0.71)$, WBC count $(\mathrm{r}=0.07, p=0.58)$, total cholesterol $(\mathrm{r}=0.12, p=0.31)$ and triglyceride levels $(\mathrm{r}=0.12, p=$ $0.29)$. The independent predictors of AF was investigated with binary logistic regression analysis, and the result is shown in Table 3.

Table 2: Comparison of laboratory parameters in the study and control groups

\begin{tabular}{lrrr}
\hline & $\begin{array}{c}\text { Control } \\
(\mathbf{n}=\mathbf{5 0})\end{array}$ & $\begin{array}{c}\text { AF recurrence } \\
(\mathbf{n = 2 2})\end{array}$ & $\boldsymbol{p}$ \\
\hline Haemoglobin, g/dL & $13.2 \pm 1.6$ & $12.2 \pm 1.9$ & 0.02 \\
Platelet, $103 / \mu \mathrm{L}$ & $222 \pm 65$ & $217 \pm 42$ & 0.91 \\
WBC, $103 / \mu \mathrm{L}$ & $7.3 \pm 1.3$ & $7.4 \pm 1.4$ & 0.52 \\
Neutrophil, $103 / \mu \mathrm{L}$ & $4.1 \pm 1.1$ & $4.4 \pm 1.5$ & 0.26 \\
Lymphocyte, $103 / \mu \mathrm{L}$ & $2.2 \pm 0.5$ & $2.1 \pm 0.4$ & 0.03 \\
Fasting glucose, mg/dL & $96 \pm 12$ & $97 \pm 14$ & 0.67 \\
Creatinine, $\mathrm{mg} / \mathrm{dL}$ & $0.85 \pm 0.25$ & $0.95 \pm 0.25$ & 0.12 \\
AST, U/L & $21 \pm 9$ & $22 \pm 8$ & 0.37 \\
ALT, U/L & $25 \pm 16$ & $27 \pm 18$ & 0.45 \\
Total cholesterol, mg/dL & $176 \pm 33$ & $184 \pm 42$ & 0.32 \\
LDL cholesterol, mg/dL & $106 \pm 28$ & $111 \pm 31$ & 0.21 \\
HDL cholesterol, mg/dL & $42 \pm 14$ & $48 \pm 12$ & 0.14 \\
Triglycerides, mg/dL & $138[112]$ & $128[105]$ & 0.48 \\
Hs-CRP, mg/L & $0.51 \pm 0.20$ & $0.69 \pm 0.21$ & $<0.01$ \\
\hline
\end{tabular}

Parametric variables without normal distribution were reported as median [interquartile range].

AF: atrial fibrillation; hs-CRP: high sensitive C-reactive protein; WBC: white blood cell count; AST: aspartate aminotransferase; ALT: alanine aminotransferase; LDL: low-density lipoprotein; HDL: high-density lipoprotein 
Table 3: Univariate and multivariate regression analysis of possible predictors of atrial fibrillation in the study population

\begin{tabular}{lcrrrr}
\hline Variables & $\begin{array}{c}\text { Unadjusted OR } \\
(\mathbf{9 5 \%} \mathbf{C I})\end{array}$ & $\boldsymbol{p}$ & $\begin{array}{c}\text { Adjusted OR } \\
\mathbf{( 9 5 \%} \mathbf{C I}) *\end{array}$ & $\boldsymbol{p}$ \\
\hline Age & $1.03(0.98,1.08)$ & 0.26 & - & - \\
Male gender & $0.56(0.21,1.56)$ & 0.28 & - & - \\
Hypertension & $1.48(0.55,4.11)$ & 0.44 & - & - \\
BMI & $1.15(0.81,1.64)$ & 0.45 & - & - \\
Glucose & $1.009(0.97,1.047)$ & 0.69 & - & - \\
Creatinine & $1.78(0.32,10.2)$ & 0.52 & - & - \\
WBC & $1.03(0.72,1.47)$ & 0.86 & - & - \\
hs-CRP & $1.54(1.18,1.99)$ & $<0.01$ & $1.41(1.02,1.94)$ & 0.04 \\
LV ejection & $0.83(0.66,1.04)$ & 0.24 & - & - \\
fraction & & & & - \\
LA & $1.32(1.13,1.54)$ & $<0.01$ & - \\
anteroposterior & & & & & \\
diameter & & & & - \\
LA volume & $1.08(1.02,1.15)$ & 0.02 & & - \\
LA volume index & $1.37(1.16,1.63)$ & $<0.01$ & $1.41(1.15,1.73)$ & $<0.01$ \\
EAT thickness & $1.23(1.04,1.47)$ & $<0.01$ & $1.34(1.05,1.71)$ & 0.02 \\
\hline
\end{tabular}

BMI: body mass index; EAT: epicardial adipose tissue; hs-CRP: high sensitive C-reactive protein; LA: left atrium; LV: left ventricle; WBC: white blood cell count

*Adjusted for hs-CRP levels, LA volume index and EAT thickness

In univariate analysis, LA anteroposterior diameter, LA volume, LA volume index, EAT thickness, haemoglobin and hs-CRP levels were significantly correlated with AF. In multivariate analysis adjusted for LA volume index, EAT thickness, haemoglobin and hs-CRP levels, only LA volume index (OR 1.41; 95\% CI: 1.15, 1.73, $p<0.01$ ), hs-CRP levels (OR 1.42; 95\% CI: 1.02, 1.94, $p=0.04$ ) and EAT thickness (OR 1.34; 95\% CI: 1.05, $1.71, p=0.02$ ) remained as independent predictors of AF recurrence in the study population.

\section{DISCUSSION}

In this study, we investigated the association between EAT thickness around the right coronary artery measured by MDCT and the rate of AF recurrences after CBA. The present study has found that EAT thickness was greater in patients who had post-ablation recurrence of AF. Left atrial volume index and preprocedural hs-CRP also predicted post-ablation AF recurrences independently.

There are various imaging tools and methods to evaluate EAT thickness. The simplest and widely available method is echocardiographic measurement of EAT, where it is measured on the right free ventricular wall in at least two locations averaging three cycles. Epicardial adipose tissue is identified as the hypoechoic space anterior to the right ventricle. Epicardial adipose tissue should not be confused with pericardial fluid and para-cardiac fat. The most critical issue is the inconsistency of measurement location due to variations of the echocardiographic window (9). Alternatively, EAT can accurately be measured by MDCT in different regions of the heart surface. Thus, the difficulty in standardizing measurement locations limits the determination of EAT reference thickness values by MDCT. The differentiation of EAT and para-cardiac fat might be difficult (10, 11). Therefore, the measurements made by MDCT are susceptible to inter-observer variability, EAT volume measurement by MDCT has become popular recently. However, this technique uses workstation to measure semi-automated volume calculations which is timeconsuming and sometimes differentiation of epicardial and paracardial fat might be problematic (12). Magnetic resonance imaging (MRI) can be used to estimate EAT by using the Simpson method which is technically difficult and patients with intra-cardiac devices cannot be scanned by MRI. Moreover, it is not widely available and the experience is limited to a small number of patients (13).

Distribution of adipose tissue is not homogenous around the heart and three-to-four-fold more fat is located around the right ventricle compared to LV. The right atrioventricular groove has the thickest fat where the RCA is located (14). In this study, we have shown that single measurement of EAT around the RCA is correlated with hs-CRP levels and may be used to predict AF recurrences after CBA. This measurement method is simpler for quantification of EAT and can be easily adopted for every patient before AF ablation.

The pathophysiologic relationship between the magnitude of EAT and AF attacks has been investigated previous studies (4-7). Anatomically, there is no separation by a physical facia between EAT, the myocardium and coronary vessels and EAT directly contacts atrial myocytes and pulmonary veins.

It is known that EAT is metabolically more active than subcutaneous fat-tissue and it produces manyinflammatory substances like cytokines, hormones and other vasoactive substances like interleukin-1, interleukin-6, TNF-alpha, resistin, MCP-1, nerve growth factor (NGF) and free fatty acids etc. It is speculated that these substances might produce undesirable effects and occurrence of AF due to their local inflammatory effects $(15,16)$ by causing a kind of local metabolic syndrome around the atria. For example, resistin which is an adipo-cytokine is secreted from adipocytes and has been shown to be associated with paroxysmal AF probably 
by activating proinflammatory cytokines, thus creating potent proinflammatory effect (17).

On the other hand, inside EAT, there is a neural network composed of both adrenergic and cholinergic nerve endings that interact with the extrinsic sympathetic and parasympathetic nervous system. Activation of these nerve structures secondary to extrinsic cardiac nerve activations, may enhance triggered activity and the development of cardiac arrhythmias (18).

Previous research showed that epicardial fat-thickness is associated with chronicity and higher recurrence rates after radio frequency CBA procedures (19-21). For example, Tsao et al (19) reported that the abundance of EAT on cardiac CT was independently related to AF recurrences after ablations in 68 patients. Nagashima et al (20) showed by three-dimensional reconstructed $\mathrm{CT}$ that greater EAT volume significantly predicted AF recurrences. Chao et al (21) showed this association by measuring EAT by TEE and noting the complexities and drawbacks of sophisticated fat measurement methods. There were several differences between the present study and these reports. Firstly, our study enrolled patients with AF ablated by cryothermal energy by second generation cryoballoon. There are limited data about EAT and post-ablation AF recurrence after using this technology for ablation. Secondly, we chose a different method to estimate EAT in order to find a simpler and easier way for EAT quantification. However, in order to claim that measurement of the EAT around the RCA is an applicable method for prediction of AF recurrences, comparative studies using other EAT measuring methods are warranted.

\section{CONCLUSION}

Epicardial adipose tissue represented by fat-thickness around the RCA was a simpler method for the quantification of epicardial fat-tissue and was found to be a predictor of AF recurrence after CBA. This method is feasible requiring less time and may help to identify patients who are at higher risk of recurrences of $\mathrm{AF}$ after CBA.

\section{AUTHORS' NOTE}

The authors declare that they have no conflict of interest.

\section{REFERENCES}

1. Camm AJ, Kirchhof P, Lip GY, Schotten U, Savelieva I, Ernst S et al. Guidelines for the management of atrial fibrillation: the Task Force for the Management of Atrial Fibrillation of the European Society of Cardiology (ESC). Eur Heart J 2010; 31: 2369-429.

2. Rosito GA, Massaro JM, Hoffmann U, Ruberg FL, Mahabadi AA, Vasan RS et al. Pericardial fat, visceral abdominal fat, cardiovascular disease risk factors, and vascular calcification in a community-based sample: the Framingham Heart Study. Circulation, 2008; 117: 605-13.

3. Gungor B. Obesity and atrial fibrillation: can adipokines help to solve this puzzle. Heart 2016; 102: 1339-40.

4. Al Chekakie MO, Welles CC, Metoyer R, Ibrahim A, Shapira AR, Cytron $\mathrm{J}$ et al. Pericardial fat is independently associated with human atrial fibrillation. J Am Coll Cardiol 2010; 56: 784-8.

5. Nakanishi K, Fukuda S, Tanaka A, Otsuka K, Sakamoto M, Taguchi H et al. Peri-atrial epicardial adipose tissue is associated with New-onset nonvalvular atrial fibrillation. Circulation J 2012; 76: 2748-54.

6. Yorgun H, Canpolat U, Aytemir K, Hazırolan T, Şahiner L, Kaya EB et al. Association of epicardial and peri-atrial adiposity with the presence and severity of non-valvular atrial fibrillation. The Int J Cardio Imaging 2015; 31: 649-57.

7. Sacks HS, John NF. Human epicardial adipose tissue: a review. Am Heart J 2007; 153: 907-17.

8. Schiller NB, Shah PM, Crawford M, DeMaria A, Devereux R, Feigenbaum $\mathrm{H}$ et al. Recommendations for quantitation of the left ventricle by two-dimensional echocardiography. American Society of Echocardiography Committee on Standards, Subcommittee on Quantitation of two-dimensional echocardiograms. J Am Soc Echocardiogr 1989; 2: 358-67.

9. Iacobellis G, Willens HJ. Echocardiographic epicardial fat: a review of research and clinical applications. J Am Soc Echocardiogr 2009; 22: 1311-9.

10. Budoff MJ, Shinbane JS. Cardiac CT imaging diagnosis of cardiovascular disease. London: Springer-Verlag London Limited: Springer e-books; 2010.

11. Gorter PM, de Vos AM, van der Graaf Y, Stella PR, Doevendans PA, Meijs MFL et al. Relation of epicardial and pericoronary fat to coronary atherosclerosis and coronary artery calcium in patients undergoing coronary angiography. Am J Cardiol 2008; 102: 380.

12. Dey D, Suzuki Y, Suzuki S, Ohba M, Slomka PJ, Polk D et al. Automated quantitation of pericardiac fat from noncontrast CT. Invest Radiol 2008; 43: $145-53$.

13. Lüchter S, Haghi D, Dinter D, Heberlein W, Kühl HP, Neff W et al. Volumetric assessment of epicardial adipose tissue with cardiovascular magnetic resonance imaging. Obesity (Silver Spring). 2007; 15: 870.

14. Preedy VR (Ed.). Handbook of anthropometry: physical measures of human form in health and disease. Springer Science and Business Media; 2012.

15. Lin YK, Chen YJ, Chen SA. Potential atrial arrhythmogenicity of adipocytes: implications for the genesis of atrial fibrillation. Medical hypotheses 2010; 74: 1026-9.

16. Friedrichs K, Anna K, Stephan B. Inflammatory pathways underlying atrial fibrillation. Trends Mole Med 2011; 17: 556-63.

17. Ozcan KS, Gungor B, Altay S, Osmonov D, Ekmekci A, Ozpamuk F et al. Increased level of resistin predicts development of atrial fibrillation. J Cardiol 2014; 63: 308-12.

18. Issac TT, Dokainish H, Lakkis NM. Role of inflammation in initiation and perpetuation of atrial fibrillation: a systematic review of the published data. J Am Coll Cardiol 2007; 50: 2021-8.

19. Tsao HM, Hu WC, Wu MH, Tai CT, Lin YJ, Chang SL et al. Quantitative analysis of quantity and distribution of epicardial adipose tissue surrounding the left atrium in patients with atrial fibrillation and effect of recurrence after ablation. Am J Cardiol 2011; 107: 1498-503.

20. Nagashima K, Okumura Y, Watanabe I, Nakai T, Ohkubo K, Kofune $\mathrm{T}$ et al. Association between epicardial adipose tissue volumes on 3-dimensional reconstructed CT images and recurrence of atrial fibrillation after catheter ablation. Circ J 2011; 75: 2559-65.

21. Chao TF, Hung CL, Tsao HM, Lin YJ, Yun CH, Lai YH et al. Epicardial adipose tissue thickness and ablation outcome of atrial fibrillation. PloS one 2013; 8: e74926.

(C) West Indian Medical Journal 2019

This is an article published in open access under a Creative Commons Attribution International licence (CC BY). For more information, please visit https://creativecommons.org/licenses/by/4.0/deed.en_US. 